\title{
Fine needle aspiration cytology of thyroid lesions and classification as per the bethesda system
}

\author{
Radhika Puri' ${ }^{1}$, Roopak Aggawal ${ }^{2, *}$, Priyanka Chadda ${ }^{3}$, Satish Sharma ${ }^{4}$, Jyoti Mishra $^{5}$ \\ ${ }^{1}$ Post Graduate 3rd Year Student, ${ }^{\mathbf{2}}$ Associate Professor, ${ }^{3,5}$ Assistant Professor, ${ }^{4}$ Professor, Dept. of Pathology, School of Medical \\ Sciences and Research, Sharda Hospital, Greater Noida, Uttar Pradesh \\ *Corresponding Author: \\ Email: drroopakaggarwal@yahoo.co.in
}

Received: $10^{\text {th }}$ October, 2017

Accepted: $22^{\text {nd }}$ December, 2017

\begin{abstract}
Aims: The objective of this study was to analyse the thyroid cytology smears by The Bethesda System for Reporting Thyroid Cytopathology (TBSRTC), to determine the distribution of diagnostic categories and subcategories, to analyse cytological feature, and to correlate cytopathology with histopathology wherever surgery was done

Materials and Methods: This is a prospective study was undertaken in the Department of Pathology, Sharda hospital, Greater Noida for a period of one year and 6 months starting from January 2016 to June 2017 .

Observation and Results: The distribution of various categories from 100 evaluated thyroid nodules were as follows: TBSRTC, $3 \%$ non-diagnostic, $92 \%$ benign, $0 \%$ AUS/FLUS, $1 \%$ Follicular neoplasm, $0 \%$ suspicious for malignancy and $4 \%$ malignant. Medullary carcinoma thyroid was misdiagnosed as adenomatoid nodule and thus not included in malignant category (category-6), but included in benign category (adenomatoid nodule).

Conclusions: TBSRTC is an excellent reporting system for thyroid FNA. It also provides clear management guidelines to clinicians to go for follow up FNA or surgery and also the extent of surgery.
\end{abstract}

Keywords: TBSRTC- The Bethesda system of reporting thyroid cytopathology, FNAC

\section{Introduction}

Thyroid lesions are one of the common conditions encountered in clinical practice. Fine needle aspiration cytology (FNAC) is widely considered as the diagnostic technique of choice in the assessment of thyroid lesions. ${ }^{1}$ It is simple, minimally traumatic and an ideal fine line diagnostic test. ${ }^{2}$

The thyroid FNAC greatly helps in the evaluation of inflammatory, infectious and neoplastic conditions. It helps especially to distinguish non neoplastic from neoplastic swellings. Its use has diminished the number of surgeries done for benign lesions and increased the proportion of malignancies in surgically resected thyroids. ${ }^{2,3}$ In the past the terminology used for reporting cytopathology of thyroid lesions has varied significantly from one laboratory to another, creating confusion in some cases. To address this issue and for clarity of communication and uniformity of terminology, National Cancer Institute (NCI) hosted". The thyroid FNA state science conference" in 2007. This NCI meeting proposed the six tiered "The Bethesda System for Reporting Thyroid Cytopathology" (TBSRTC). ${ }^{4,5}$

Each report begins with 6 general diagnostic categories with some categories having two alternative names and some having degree of sub categorization. Each of the categories has an implied cancer risk (ranging from $0 \%$ to $3 \%$ for the benign category to virtually $100 \%$ for the malignant category) that links it to a rational clinical management guideline. ${ }^{6}$
The Bethesda System for Reporting Thyroid Cytopathology (TBSRTC), thus emphasizing its significance for diagnosis. This assesses the accuracy of TBSRTC. The National Cancer Institute (NCI) has put forward the Bethesda System for Reporting Thyroid Cytopathology (TBSRTC) which divides thyroid lesions into 6 diagnostic categories. ${ }^{7}$

\section{Materials and Methods}

This is a prospective study was undertaken in the Department of Pathology, Sharda hospital, Greater Noida for a period of one year and 6 months starting from January 2016 to June 2017 onwards. The study consisted of 100 patients who presented with the history of swelling of thyroid which were referred from the Departments of Surgery, Medicine and ENT.

The patients underwent detailed clinical examination and a careful palpation of the thyroid was done to guide precisely the location for doing aspiration. Details of the procedure were explained and informed written consent will be obtained from all patients undergoing FNAC of thyroid lesions. Taking all aseptic precautions FNAC was performed in supine position after hyperextending the neck with a pillow under the shoulder so as to make the thyroid prominent. Using 19-24 G needle \& $10 \mathrm{ml}$ syringe using conventional technique, aspiration was done. The patient was instructed to refrain from swallowing during the procedure.

After aspiration material was expelled onto a clean labelled glass slide. The same procedure was repeated 
at different site depending upon the quantity and quality of aspirate material obtained. Half of the smears will be fixed in $90 \%$ alcohol \& stained with H\& E. Remaining half will be air dried \& stained with Giemsa stain. Ultrasound guided FNAC was done wherever clinically warranted.

Out of the 100 patients, 21 patients underwent surgical removal of the lesion the specimens were received in containers containing $10 \%$ formalin solution in the department. Detailed gross examination was done and sections were taken from representative areas for paraffin embedding. Results of cytological and histopathological studies were later correlated to evaluate the efficacy of FNAC.

\section{Observation and Results}

FNAC was done on 100 patients with thyroid lesions over a period of $1 \frac{1}{2} 2$ years. The following observations were made in our study. The age group of patients ranged from $16-76$ years with mean age of 46 years. In the present study, it has been observed that the incidence of thyroid lesions were more in the age group of 21-30 yrs with 30 cases, and least common in the age group of 71-80 yrs with 4 cases. The youngest patient was 16 yrs female and oldest was 76 yrs female.

Majority of patients were females accounting for $80 \%$ and males were $20 \%$. Male to female ratio was 1:4.

Among the total thyroid lesions, Non- neoplastic constituted $92 \%$, neoplastic lesions were 5\% and 3\% were Non-diagonistic.

Among the 92 non-neoplastic lesions, incidence was high in the age group 21-30 years with 28 cases, followed by 24 cases in the age group 31-40, 17 cases in age group 41-50 years, 10 cases in age group 11-20 years, 6 cases in 61-70 year age group, 4 cases in 71-80 years and 3 cases in 51-60 years. The incidences of non-neoplastic lesions were more in females. Out of total 92 cases, 72 patients were females and 20 were males.

The most common lesion found on FNAC was nodular goiter with 40 cases and least common was Grave's disease with 1 case.

In FNAC of 100 cases, there were 5 cases of neoplastic lesions. Five cases of malignancy were diagnosed on FNAC. On FNAC, there were 4 cases of papillary carcinoma and one case of Follicular neoplasm. Follicular carcinoma was included under the neoplastic/malignant category as the tumor cells showed atypical features such as pleomorphism, prominent nucleoli, hyperchromasia and capsular invasion. On histopathological examination, Follicular carcinoma thyroid and two cases of papillary carcinoma thyroid were confirmed. One case misdiagnosed as adenomatoid nodule on FNAC was confirmed to be medullary carcinoma thyroid on histopathology. The reason for misdiagnosis being scanty number of cells showing plasmacytoid features and lack of amyloid fragment. All neoplastic cases were predominantly seen in females, except for 1 case of papillary carcinoma in male.

In our study the incidence of neoplastic lesions was high in the age group 41-50 years. It was low in younger age group.

Categorizing the cytological pattern according to TBSRTC: In this present study, using TBSRTC, the lesions were classified as 3\% non-diagnostic, 92\% benign, 0\% AUS/FLUS, 1\% Follicular neoplasm, 0\% suspicious for malignancy and $4 \%$ malignant.

There were originally 5 non-diagonistic/ unsatisfactory cases, out of which 2 patients underwent ultrasound-guided repeat FNAC and were diagnosed as colloid goiter, thus included in the benign category (category-2). But 3 cases remained undiagonostic and remained in category-1. The 2 undiagnostic cases contained fewer than six groups of benign follicular cells and one case contained cyst fluid only along with few benign looking follicular cells.

\section{Histopathological Diagnosis of the Lesions}

In the present study of 100 cases, 21 patients underwent surgery and the histopathological diagnosis of the cases are given below:

Non neoplastic lesions - 17

Neoplastic lesions -4

Cytohisto-histopathological correlation in the present study was observed in 21 cases. Among the non-neoplastic lesions diagnosed by cytology, histopathological study was possible in 18 cases. Whereas in neoplastic cases histopathology was done in 3 cases. In the present study, on comparison allneoplastic lesions were correctly diagnosed cytologically and histopathologically. While among non-neoplastic lesions, one case was incorrectly diagnosed cytologically. Accuracy rate of correct diagnosis by FNAC was achieved in $100 \%$ of malignant cases and $94.44 \%$ in non-malignant cases. Total accuracy of the FNAC in the study is $95.23 \%$.

\section{Non-Diagnostic}

There were 5 non-diagnostic/unsatisfactory cases. 2 smears were poorly prepared or showed obscured follicularcells, thus the patients underwent ultrasoundguided repeat FNAC and were diagnosed as colloid goiter, which was included in the benign category (category-2). The other 3 cases showed cyst fluid only and fewer than six groups of ten benign follicular cells. Thus, the three cases did not undergo reaspiration and finally remained in the Non-diagnostic category (Category-1) of our study.

Colloid Goiter Cytological diagnosis of colloid goiter was made in 35 cases in this study. There were two cases which were non-diagnostic or unsatisfactory thus they underwent ultrasound-guided repeat FNAC and were then diagnosed as colloid goiter. 
Table 1: Features in cytologically diagnosed cases of colloid goiter [Fig. 1]

\begin{tabular}{|l|c|c|}
\hline S No. & Cytological features & $\begin{array}{c}\text { Number of } \\
\text { aspirates }\end{array}$ \\
\hline 1 & Groups of follicular cells & 32 \\
\hline 2 & $\begin{array}{c}\text { Disorganised clusters or } \\
\text { cells }\end{array}$ & 08 \\
\hline 3 & Mixed pattern & 28 \\
\hline 4 & Macrophages & 05 \\
\hline 5 & Moderate colloid & 08 \\
\hline 6 & Abundant colloid & 05 \\
\hline 7 & $\begin{array}{c}\text { RBCs, sparse } \\
\text { lymphocytes }\end{array}$ \\
\hline
\end{tabular}

Out of the 35 cases of colloid goiter observed on FNAC or cytologically, 5 cases were subjected to histopathology examination and diagnosis of colloid goiter was confirmed. [Fig. 1]

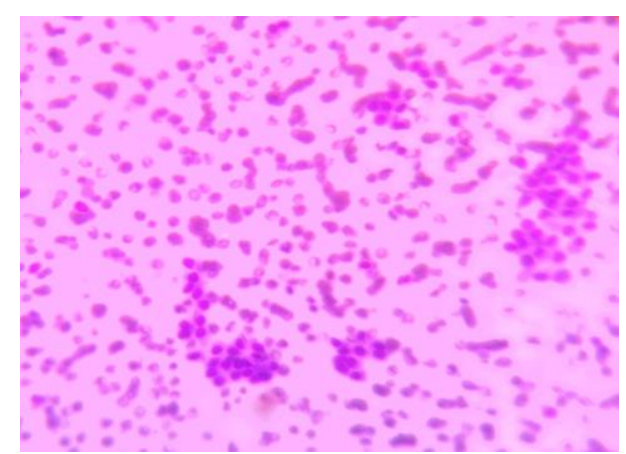

Fig. 1: Colloid Goiter, smear shows scattered groups of follicular cells in background of abundant thin colloid (100X)( H\&E stain)

\section{Nodular Goiter}

There were 40 cases in which diagnosis of nodular goiter was made on thyroid aspirate.

Table 2: Features in cytologically diagnosed cases of nodular goiter

\begin{tabular}{|l|c|c|}
\hline S. No. & Cytological features & $\begin{array}{c}\text { Number of } \\
\text { aspirates }\end{array}$ \\
\hline 1. & $\begin{array}{c}\text { Clusters of follicular } \\
\text { cells }\end{array}$ & 40 \\
\hline 2. & Singly lying cells & 37 \\
\hline 3. & Macrophages & 7 \\
\hline 4. & Scanty colloid & 6 \\
\hline 5. & $\begin{array}{c}\text { Moderate -Abundant } \\
\text { colloid }\end{array}$ & 36 \\
\hline 6. & Absent colloid & 02 \\
\hline 7. & RBCs, lymphocytes & 14 \\
\hline
\end{tabular}

Grave's Disease: The diagnosis of Grave's disease was made in 1 case of 35 year old female. The cytology showed follicular cells in sheets and clusters. Cells are tall with finely granular cytoplasm, marginal vacuoles, flame cells (fire-flare appearance) and basal nuclei.

\section{Lymphocytic/ Hashimoto's Thyroiditis}

Cytological diagnosis of lymphocytic thyroiditis was made in 15 cases in this study. Groups of follicular and hurthle cells were seen in all the cases. The pattern of arrangement of cells was loosely cohesive clusters and tiny sheets. The colloid was scant in both the cases. Dispersed lymphocytes were seen in the background with the formation of lymphoid follicles. [Fig. 2]

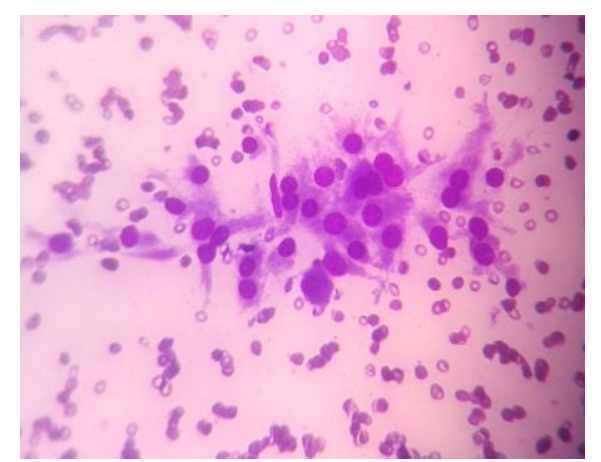

Fig. 2: Lymphocytic thyroiditis, cluster of hurthle cells having abundant granular cytoplasm and mild anisonucleosis (400X)(MGG)

Follicular Neoplasm: Cytological diagnosis of follicular neoplasm was made in 1 case. Smears were cellular and compact microfollicular cell clusters were observed. Follicular cells were also seen arranged in groups and sheets. Mild to moderate nuclear enlargement and nuclear hyperchromasia was observed. Nuclear overlapping was seen. Chromatin was coarse [Fig. 3]. The case was subjected to histopathological examination which confirmed the diagnosis of follicular carcinoma.

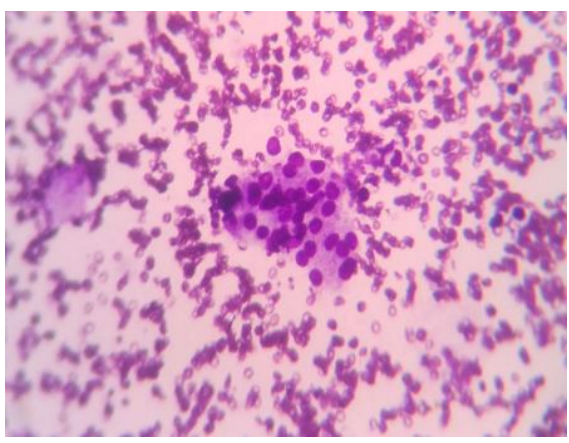

Fig. 3: Follicular neoplasm follicular cells arranged in follicular clusters $(\mathbf{4 0 0 X})$ (MGG)

Papillary Carcinoma: Four patients were diagnosed with papillary carcinoma on cytological aspirate. Smears showed multiple follicular cells arranged in sheets and papillary fragments. These cells are pleomorphic with scant cytoplasm, anisonucleosis with coarse chromatin. Nuclear overlapping was observed in 
all cases. Scant stringy colloid was also seen. Intranuclear inclusions and presence of psammoma bodies was seen in some cases [Fig 4]. One case (of 45 year old female) was subjected for histopathological examination which confirmed it as well differentiated encapsulated papillary carcinoma.

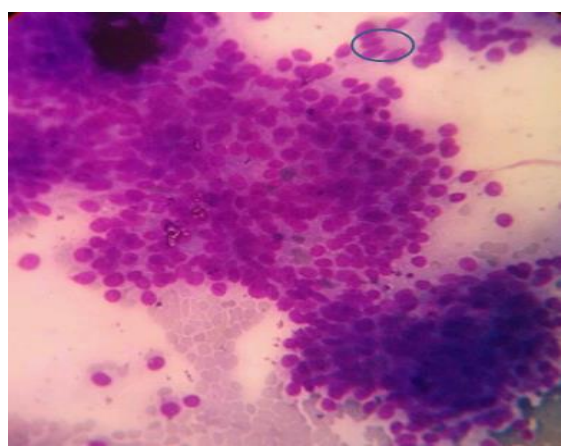

Fig. 4: Papillary carcinoma thyroid cells arranged in papillae with fibrovascular cores. (400X)(MGG)

Medullary Carcinoma: One case was reported as medullary carcinoma. Syncytial like clusters alternating with isolated cells were seen. Cells were plasmacytoid and polygonal. Moderate pleomorphism was seen. Nucleoli were prominent in few cells. Chromatin was granular "salt and pepper" in appearance. Amyloid was absent. There was no tumor metastases.

Histopathological examination was done, which confirmed it to be medullary carcinoma of the thyroid.

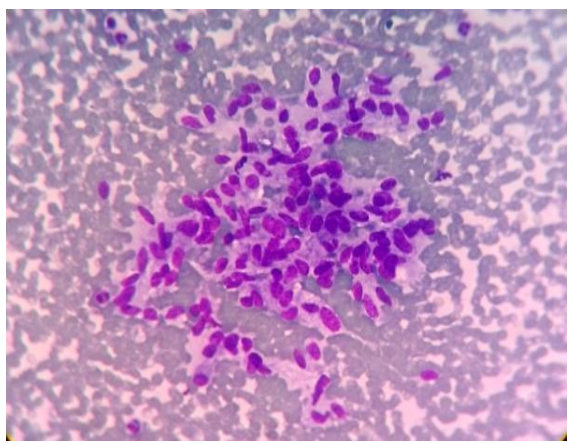

Fig. 5: Medullary carcinoma thyroid clusters of loosely cohesive cells. Cells are plasmacytoid and spindle shaped (400X)(MGG)

\section{Discussion}

Fine needle aspiration cytology is the fundamental method for evaluation of thyroid lesions. This study deals with FNAC of thyroid performed in 100 patients during one and a half year time period. Of these, majority (80\%) were females. Males accounted for $20 \%$ with a female to male ratio of $4: 1$. In our study, it was observed that majority of cases were in the age group 21-30 years. The mean age was 37 years.

Age distribution of the present study was comparable to other studies. According to study by Rahman MA, the peak frequency of the patients were in the third decade $(36.11 \%)$, followed by fourth decade $(24.07 \%) .{ }^{8}$ Similar findings were obtained in present study, maximum number of patients were in the third decade (30\%) followed by fourth decade of life (27\%).

Sex distribution of the lesions was also comparable with that of the other studies. Majority of the patients in our study were in euthyroid state. Most common presenting complaint was neck swelling. Observation made in this regard was comparable to the study done by Chetna J Mistry. ${ }^{9}$

Table 3: Comparative incidence of non-neoplastic and neoplastic lesions

\begin{tabular}{|l|c|c|c|}
\hline Studies & Non neoplastic & Neoplastic & Ratio \\
\hline Bhartiya R et al $^{(10)}$ & $89.44 \%$ & $10.56 \%$ & $8.47: 1$ \\
\hline PK Bagga \& NC Mahajan $^{(1)}$ & $92.1 \%$ & $7.9 \%$ & $11.66: 1$ \\
\hline Htwe et al $^{(1)}$ & $93.3 \%$ & $6.7 \%$ & $13.9: 1$ \\
\hline Present study & $92 \%$ & $5 \%$ & $18.4: 1$ \\
\hline
\end{tabular}

Nodular goiter $(40 \%)$ was the most common thyroid lesion in this study, followed by colloid goiter. Cytological presentation in nodular goiter is as varied as its histology. Colloid was present in most of the lesions. $15 \%$ cases were lymphocytic. The predominant pattern of arrangement of cells in this lesion was normo/macrofollicular and disorganized clusters. Study done by Basavaraj P Bommanahalli et al showed similar findings and stated that the differential diagnoses of smears with predominantly normo/macrofollicular pattern most often included nodular goitre and follicular neoplasm. ${ }^{12}$

Chetna $\mathbf{J}$ Mistry et $\mathrm{al}^{9}$ and Neiki et $\mathrm{al}^{13}$ stated that the presence of degenerative changes in monolayered sheets and abundant colloid would suggest a possibility of non-neoplastic lesion.

Cytological diagnosis of colloid goiter was made in 33 cases. All the smears were colloid rich with monomorphic follicular cells. 17 cases were subjected to histopathology examination revealed diagnosis of colloid goiter in 17 cases. In the study by Das DK et al, 
colloid goiter, cellular adenomatoid nodule (hyperplastic nodule), hyperplastic nodule/ follicular neoplasm and follicular neoplasm form a continuous spectrum in terms of cellularity and presence of micro follicles in increasing order, and background colloid, in decreasing order. ${ }^{14}$

Follicular neoplasm was seen in 1 case in the present study. Most of the patients presented with a nodular swelling. Aspirates were cellular and compact microfollicular cell clusters with groups of follicular cells were observed in all these cases. In the study of P. Bommanahalli, microfollicular pattern was predominantly seen in follicular neoplasm. Cellularity, nuclear size, pleomorphism of cells and amount of colloid are helpful to distinguish neoplastic from nonneoplastic follicular lesions. ${ }^{12}$

In a study done by Heydar Ali Esmaili, 296 cases $(17.81 \%)$ were classified under Follicular Neoplasm which cannot be distinguished from nodular hyperplasia. ${ }^{15}$

Among the malignant lesions, the most common lesion observed both on FNAC and histopathologically was papillary carcinoma. In studies by Tabaqchali et al, Bhatta $\mathrm{S}$ et al also, papillary carcinoma was the most commonly observed malignant lesion. ${ }^{16,17}$

Papillary carcinoma was the most common malignant lesion encountered in the present study with four cases, out of which one case only underwent surgery and was confirmed histopatholgically.

Medullary carcinoma of the thyroid was reported in one case. It was misdiagnosed on FNAC as adenomatoid hyperplasia but on histopathological examination was confirmed to be medullary carcinoma. Cells were arranged in loose syncytial aggregates. There were spindle shaped cells and few plasmacytoid cells. Amorphous acellular pinkish amyloid material was not seen.

Table 4: Comparison of diagnostic accuracy

\begin{tabular}{|c|c|}
\hline Studies & Diagonistic accuracy \% \\
\hline Goswami et al $^{(18)}$ & $93.33 \%$ \\
\hline Bhartiya $\mathrm{R}$ et al ${ }^{(10)}$ & $97.1 \%$ \\
\hline Present study & $95.23 \%$ \\
\hline
\end{tabular}

The total accuracy of the FNAC in the study is 95.23\%.This was comparable to other studies like study by Goswami et al, ${ }^{18}$ where total diagonistic accuracy was $93.33 \%$ and Bhartiya $\mathrm{R}^{10}$ et al, where accuracy was $97.1 \%$.

\section{Conclusion}

TBSRTC is an excellent reporting system for thyroid FNA. It also provides clear management guidelines to clinicians to go for follow up FNA or surgery and also the extent of surgery.

\section{List of Abbreviations}

TBSRTC: The Bethesda system of reporting thyroid cytopathology

FNAC: Fine Needle Aspiration Cytology

AUS/FLUS: Atypia of Undetermined Significance/ Follicular Lesion of Undetermined Significance

FN: Follicular Neoplasm

H\& E: Haematoxylin and Eosin

HPE: Histopathological examination

MGG: May Grunwald Giemsa

ND/UNS: Non Diagnostic/ Unsatisfactory

SFN: Suspicious of follicular neoplasm

\section{References}

1. Bagga PK, Mahajan NC. Fine needle aspiration cytology of thyroid swellings: how useful and accurate is it? Indian J Cancer. 2010 Oct-Dec;47(4):437-42.

2. Orell SR. Sterrett GF. Fine needle aspiration cytology, $5^{\text {th }}$ ed. London, Churchill Livingstone: Elsevier, 2012:118-155.

3. Agrawal R, Saxena M, Kumar P. A study of fine needle aspiration cytology of thyroid lesions with histopathological correlation. IJPO2015;2(4):277-83.

4. Cibas E S, Sanchez M A. "The national cancer institute thyroid fine-needle aspiration state-of-the science conference: inspiration for a uniform terminology linked to management guidelines." Cancer Cytopathology 2008;114:71-3.

5. Baloch Z W, Livolsi V A, S Asa L. Diagnostic terminology and morphologic criteria for cytologic diagnosis of thyroid lesions: a synopsis of the national cancer institute thyroid fine needle aspiration state of the science conference. Diagnostic Cytopathology 2008;36(6):425-37.

6. Bongiovanni M, Spitale A, Faquin WC, Mazzucchelli L, Baloch ZW. The Bethesda System for Reporting Thyroid Cytopathology: a meta-analysis. Acta Cytol 2012;56(4):33339.

7. Edmund S. Cibas, Syed Z. Ali: The Bethesda System for Reporting Thyroid Cytopathology: Am J Clin Pathol 2009:132:658-665.

8. Rahman MA, Biswas MA, Siddika ST, Sidker AM Talukder SI, Alamgiri MH. Histomorphological pattern of Thyroid lesion. Dinajpur Med Col J 2013 Jul;6(2):134-140.

9. Chetna J Mistry, T.Y. Vijaypura, Rupti K Pande. Cytopathological correlation of Thyroid Swelling. IJSR; Aug 202; Volume 1 (3):75-76.

10. Bhartiya R, Mallik M, Kumari N, Prasad BN. Evaluation of thyroid lesions by fine-needle aspiration cytology based on Bethesda system for reporting thyroid cytopathology classification among the population of South Bihar. Indian journal of medical and paediatric oncology. 2016 Oct;37(4):265-70.

11. Htwe T T, Hamdi M M, Swethadri G K, Wong J O L, Soe M M, Abdullah M S. Incidence of thyroid malignancy among goitrous thyroid lesions from the Sarawak General Hospital 2000-2004. Singapore Med J 2009;50(7):724.

12. Bommanahalli BP, Bhatt RV, Rupnarayan R. A cell pattern approach to interpretation of fine needle aspiration cytology of thyroid lesions: A cytohistomorphological study J. Cytol. 2010 Oct;27(4):127-32.

13. Neiki NS, Kazal HL. Solitary thyroid nodule - an insight. JIACM 2006;7(4):328-33.

14. Das DK, Khanna CM. Tripathi RP, Pant CS, Mandal AK, Chandra $\mathrm{S}$ et al. Solitary nodular goiter. Review of 
cytomorphologic features in 441 cases.

Acta cytol 1999;43:563-74.

15. Esmaili HA and Taghipour H. Fine-Needle Aspiration in the Diagnosis of Thyroid Diseases: An Appraisal in Our Institution. ISRN Pathology, Volume 2012, Article ID 912728, doi: $10.5402 / 2012 / 912728$.

16. MA Tabaqchali, JM Hanson, SJ Johnsont, V Wadehrat. TWJ Lennard, G Proud. Thyroid aspiration cytology in Newcastle: A six year cytology/histology correlation study. Ann R Coll Surg Engl 2000;82:149-155.

17. Bhatta S, Makaju R, Mohammad A. Role of fine needle aspiration cytology in the diagnosis of thyroid lesions. Journal of Pathology of Nepal (2012) Vol. 2, 186-188.

18. Goswami D, Agrawal P, Shinde P. Accuracy of fine needle aspiration cytology (FNAC) in comparison to histopathological examination for the diagnosis of thyroid swellings. International Journal of Medical Science and Public Health. 2017 Jan 1;6(1):6-11. 